\title{
Dynamics of Lymphocyte Populations during Trypanosoma cruzi Infection: From Thymocyte Depletion to Differential Cell Expansion/Contraction in Peripheral Lymphoid Organs
}

\author{
Alexandre Morrot, ${ }^{1,2}$ Juliana Barreto de Albuquerque, ${ }^{1}$ Luiz Ricardo Berbert, ${ }^{1}$ \\ Carla Eponina de Carvalho Pinto, ${ }^{1,3}$ Juliana de Meis, ${ }^{1}$ and Wilson Savino ${ }^{1}$ \\ ${ }^{1}$ Laboratory on Thymus Research, Oswaldo Cruz Institute, Oswaldo Cruz Foundation, \\ 21045-900 Rio de Janeiro, RJ, Brazil \\ ${ }^{2}$ Department of Immunology, Microbiology Institute, Federal University of Rio de Janeiro, 21941-590 Rio de Janeiro, RJ, Brazil \\ ${ }^{3}$ Institute of Biology, Fluminense Federal University, 24020-140 Niterói, RJ, Brazil
}

Correspondence should be addressed to Wilson Savino,w_savino@hotmail.com

Received 12 August 2011; Accepted 17 October 2011

Academic Editor: Luis E Cuevas

Copyright ( 12012 Alexandre Morrot et al. This is an open access article distributed under the Creative Commons Attribution License, which permits unrestricted use, distribution, and reproduction in any medium, provided the original work is properly cited.

\begin{abstract}
The comprehension of the immune responses in infectious diseases is crucial for developing novel therapeutic strategies. Here, we review current findings on the dynamics of lymphocyte subpopulations following experimental acute infection by Trypanosoma cruzi, the causative agent of Chagas disease. In the thymus, although the negative selection process of the T-cell repertoire remains operational, there is a massive thymocyte depletion and abnormal release of immature CD $4^{+} \mathrm{CD} 8^{+}$cells to peripheral lymphoid organs, where they acquire an activated phenotype similar to activated effector or memory T cells. These cells apparently bypassed the negative selection process, and some of them are potentially autoimmune. In infected animals, an atrophy of mesenteric lymph nodes is also observed, in contrast with the lymphocyte expansion in spleen and subcutaneous lymph nodes, illustrating a complex and organ specific dynamics of lymphocyte subpopulations. Accordingly, T- and B-cell activation is seen in subcutaneous lymph nodes and spleen, but not in mesenteric lymph nodes. Lastly, although the function of peripheral CD4 $4^{+} \mathrm{CD} 8^{+} \mathrm{T}$-cell population remains to be defined in vivo, their presence may contribute to the immunopathological events found in both murine and human Chagas disease.
\end{abstract}

\section{Introduction}

Trypanosoma cruzi is the causative agent of Chagas disease affecting more than 10 million people in Latin America. The parasite is transmitted by feces of infected insect vectors belonging to the family Reduviidae [1-3]. After infection, the initial acute phase of the disease progresses to an asymptomatic indeterminate period with virtually undetectable parasitemia and a strong humoral and cellular anti-T. cruzi responses. Up to several years after the initial infection, approximately 20 to $30 \%$ of all infected individuals develop a chronic inflammatory disease primarily affecting the heart [2-4]. Although different mechanisms have been proposed to trigger this pathology, there is a growing body of evidence that parasite persistence is associated with a chronic inflammatory response, which is the primary cause of Chagas disease $[5,6]$.

Experimental models of $T$. cruzi infection have been widely used to study various aspects of the infection. Acute infection in mice leads to strong activation of innate and adaptive immune response $[7,8]$. In the course of infection, there is a fine change in the dynamics on the size of lymphocyte populations that contributes to regional specificities of the immune response in central and peripheral lymphoid organs: while there is an expansion in peripheral lymphoid organs such spleen and subcutaneous lymph nodes due to 
$\mathrm{T}$ and $\mathrm{B}$ cell polyclonal activation, we have observed an atrophy of the thymus and mesenteric lymph nodes in the infection [9]. The atrophy in such lymphoid organs seems to be associated with differences in lymphocyte proliferation and death [10-16].

In the thymus, we and others have identified that the severe thymic atrophy in acutely infected animals is mainly due to apoptotic depletion of $\mathrm{CD}^{+} \mathrm{CD}^{+}$double-positive (DP) thymocytes undergoing differentiation $[13,14,17-$ 25]. However, regardless of thymic changes promoted by the acute $T$. cruzi infection, we have showed that the negative selection remains functional [26].

In a second vein, we have showed that, in contrast with the physiological condition, there is an abnormal release of DP thymocytes into the periphery during the course of the T. cruzi infection $[12,13]$ and that these cells acquire an activated phenotype similar to what is described for activated single-positive T cells [26].

The dynamics of cell populations in various lymphoid organs during the infection may reflect differential profiles of the adaptive immune response driving lymphocyte fluctuations in distinct compartments of the immune system. The impact of these alterations during the parasite infection is still unknown. Yet, it is conceivable that an abnormal release of nonselected thymocytes during acute infection may have an impact on the host immune responses against the parasite. In the present paper we will focus recent data concerning the thymic atrophy during the course of acute T. cruzi infection, as well as the dynamics of lymphocyte subsets in distinct secondary lymphoid tissues.

\section{Thymus Atrophy and the Negative Selection of Thymocytes in Chagas Disease}

Several pathogens, including T. cruzi, cause thymic atrophy [17]. The mechanisms underlying this phenomenon are most likely linked to a particular pathogen-host relation established during infection. In the T. cruzi model, it has been shown that the inflammatory syndrome mediated by TNF- $\alpha$ during the acute phase of infection induces the activation of hypothalamus-pituitary-adrenal (HPA) axis with the consequent release of corticosterone [18, 27, 28]. The glucocorticoid rise is likely associated with profound effects on the changes observed in the thymuses of T. cruziinfected mice, including the lymphoid and nonlymphoid compartments.

Yet, the thymic atrophy triggered by $T$. cruzi is more complex, with other host-derived molecules likely being involved. For example, thymic atrophy is not seen in $T$. cruzi-infected galectin-3 knockout mice [19]. On the other hand, the parasite-derived transsialidase is involved in the generation of intrathymic T-cell death $[21,25,29]$.

The thymic microenvironmental changes seen after acute infection comprise the enhanced expression of extracellular matrix ligands and receptors, which correlates with a higher fibronectin-driven migration of DP thymocytes, and the abnormal raise of immature DP cells in lymph nodes $[8,12$, $13,30]$.
Recently, we have determined whether the changes of the thymic microenvironment seen following T. cruzi infection, would also lead to an altered intrathymic negative selection of the T-cell repertoire. It is largely established that interactions between TEC and thymocytes control the development of the thymic microenvironment and T-cell development. Previous studies have shown that the disruption of normal thymic architecture is known to affect the expression pattern of autoantigens by TEC and functionality of thymus [3133]. Thymic medullary atrophy and decreased expression of Aire and TRAs have been reported in mouse models deficient in several genes involved in the $\mathrm{NF} \kappa \mathrm{B}$ pathway, suggesting an important role of this pathway in the development of thymic medulla [34]. We showed that the expression of Aire and highly selective tissue-restricted antigens was readily detectable in whole thymus by real-time PCR analysis from infected mice, rather similar to controls. These data suggest that the expression of peripheral antigens in the infected thymuses is sufficient to modulate the tolerance induction by the negative selection process [26].

As the acute phase of infection progresses, the thymic atrophy becomes evident, as is the increase in numbers of apoptotic intrathymic DP cells, compared to their respective normal counterparts. Although this phenomenon may be a consequence of the changes observed in the organ, our data show that along the DP depletion there is sustained expression of Bim, proapoptotic factor essential for thymocyte negative selection. Finally, by using an OTII TCR transgenic system, we were able to demonstrate that the administration of the cognate OVA peptide in the acutely infected mice undergoing thymic atrophy can induce TCRstimulation-induced apoptosis of semimature thymocytes. These data point out that negative selection operates normally during infection-promoted thymic atrophy, since the DP cells can be negatively selected in the infected thymus by antigen-induced depletion [26]. This supports previous work showing that intrathymic mature singlepositive $\mathrm{CD}^{+}$or $\mathrm{CD}^{+} \mathrm{T}$ cells do not bear forbidden TCR genes as compared with their DP counterparts undergoing intrathymic differentiation [12].

\section{Dynamics of Lymphocyte Populations in Peripheral Lymphoid Organs in Chagas Disease}

The intrinsic balance among the lymphoid organs dictating the functional properties of the lymphocyte subsets are critical for establishing the immune response to T. cruzi infection [9]. Although the intrathymic checkpoints necessary to avoid the maturation of T cells expressing a forbidden T-cell receptor repertoire are present in the acute phase of murine Chagas disease, it has been shown that significant amounts of double-negative and double-positive thymocytes (Figure 1) are abnormally released from infected thymus to the periphery $[12,13,35]$. Considering that among thymus-derived $\mathrm{CD} 4^{+} \mathrm{CD} 8^{+}$lymphocytes exhibit potentially autoimmune TCRs, we raised the hypothesis that they could be activated in peripheral lymphoid organs. This prompted 


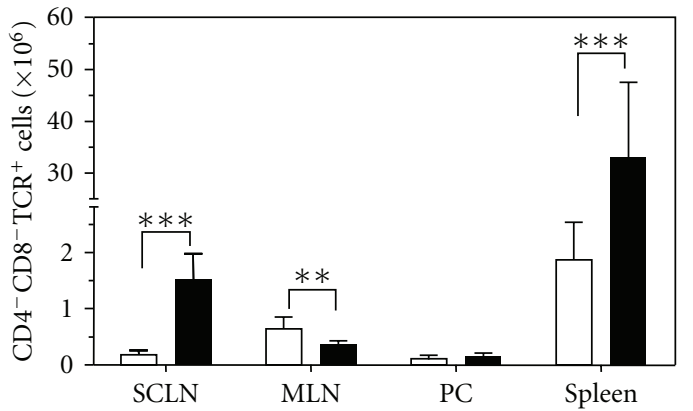

(a)

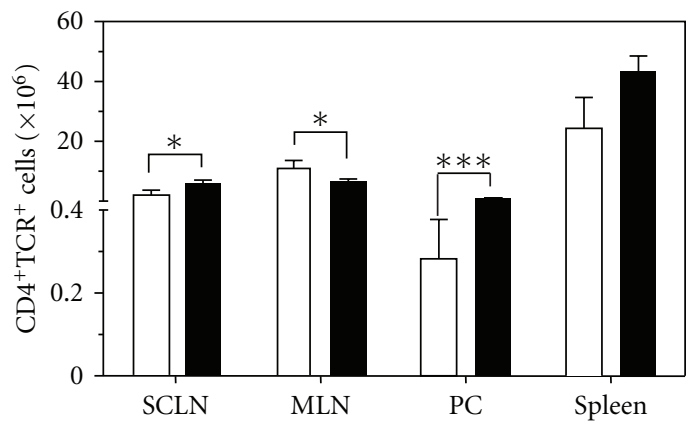

(c)



(e)

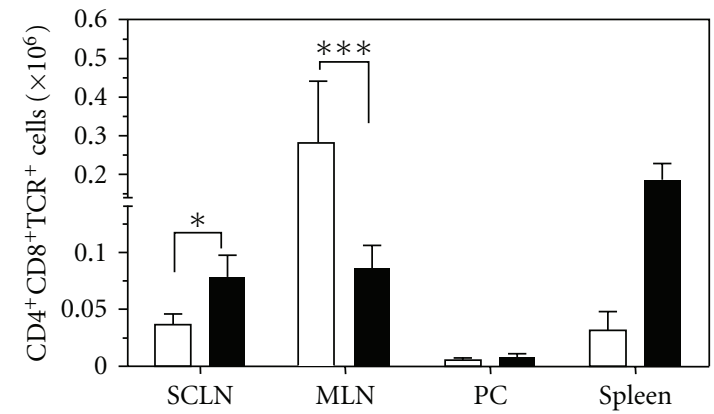

(b)

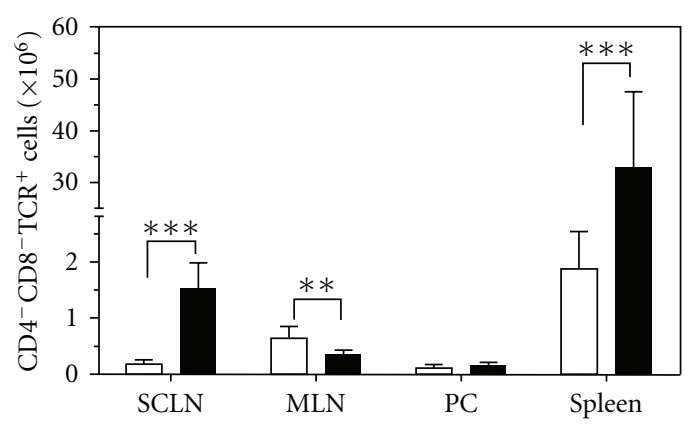

(d)

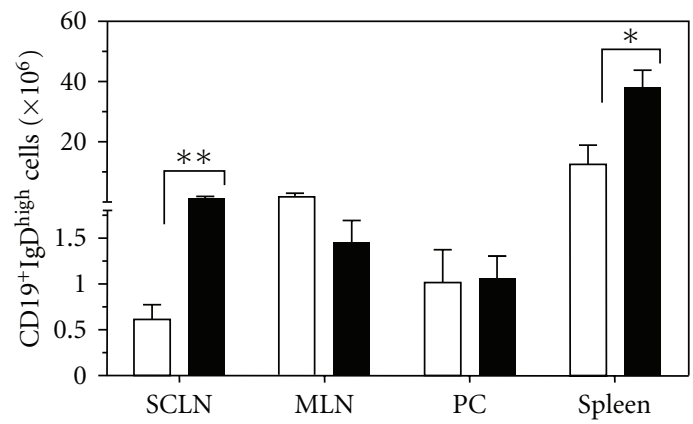

(f)

FIGURE 1: Lymphocyte subsets in central and peripheral lymphoid organs from T. cruzi acutely infected mice. Male BALB/c mice were infected intraperitoneally with $10^{2}$ culture-derived trypomastigotes of T. cruzi (Tulahuén strain), and 14 days after infection the subcutaneous lymph nodes (SCLN), mesenteric lymph nodes (MLN), peritoneal cavity cells (PC), and spleen were harvested to perform flow cytometry. Erythrocytes were previously depleted in the spleen cell suspensions by treatment with Tris-buffered ammonium chloride. The total number of (a) double-negative CD4 ${ }^{-} \mathrm{CD} 8^{-} \mathrm{T}$ cells, (b) double-positive $\mathrm{CD} 4^{+} \mathrm{CD} 8^{+} \mathrm{T}$ cells, (c) single-positive $\mathrm{CD} 4^{+} \mathrm{T}$ cells, and (d) CD8 ${ }^{+} \mathrm{T}$ cells, (e) $\mathrm{CD}_{1} 9^{+} \mathrm{IgD}^{\text {low }} \mathrm{B}$ cells and (f) $\mathrm{CD} 9^{+} \mathrm{IgD}^{\text {high }} \mathrm{B}$ cells are indicated for each histogram. Values represent the mean and standard error. The infected group $(n=5-14)$ were compared to noninfected controls $(n=4-9)$ with $t$-test, using the program GraphPad Prism 5 . Data were considered significant if $P$ values were $<0.05$. ${ }^{*} P<0.05,{ }^{*} P<0.01,{ }^{* * *} P<0.001$.

us to evaluate in acutelyinfected mice whether those cells exhibited an activated profile similar to effector/memory single-positive $\mathrm{T}$ cells. The existence of this unconventional and rare $(<5 \%)$ lymphocyte population in the periphery was explained as a premature release of DP cells from the thymus into the periphery, where their maturation into functionally competent single-positive cells continues $[12,35]$. There is, however, considerable evidence of an increased frequency of peripheral $\mathrm{CD} 4^{+} \mathrm{CD} 8^{+} \mathrm{T}$ cells during viral infections and during acute T. cruzi infection. For example, in human immunodeficiency virus or Epstein-Barr virus infections, the percentage of DP cells can increase to $20 \%$ of all circulating lymphocytes [36, 37]. This fluctuation is also present in the secondary lymph nodes as we demonstrated in the experimental model of Chagas disease, in which DP cell subset increases up to 16 times in subcutaneous lymph nodes $[12,13]$.

There is an increase in IL-2 production which has been associated with the hyperplasia in the subcutaneous lymph nodes during T. cruzi infection $[9,10]$. Peripheral lymphoid organs play a role on the immunity against $T$. cruzi infection. For instance, it has been shown that splenocytes and mesenteric lymph nodes cells are involved in the host immune response since splenectomy or mesenteric lymph 


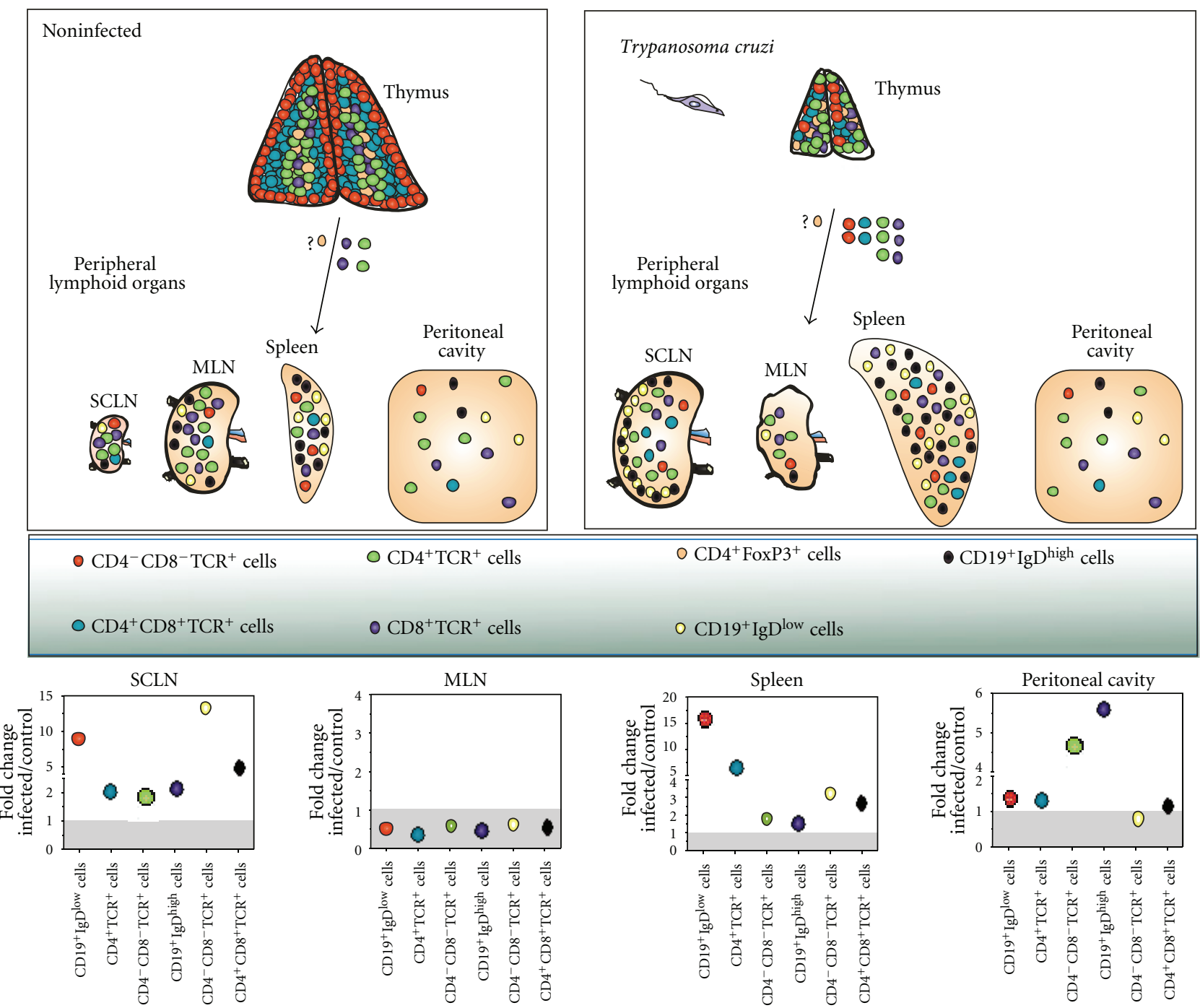

FIGURE 2: Distinct pattern of lymphocyte fluctuations in central and peripheral lymphoid organs during acute Trypanosoma cruzi infection. The upper panels depict thymus and peripheral lymphoid sites, in terms of T- and B-cell subsets. It is illustrated the thymic atrophy, simultaneously with an increase in mature and immature export of cells from the organ, as well as hyperplasia of spleen and subcutaneous lymph nodes that course in parallel with an atrophy of the mesenteric lymph nodes, whereas the peritoneal cavity remains rather unchanged (except for the significant rise in $\mathrm{CD}^{+}$and $\mathrm{CD}^{+}$T-cell subsets). Bottom panels reveal fold changes of each $\mathrm{T}$ - and B-lymphocyte subsets from acutely infected mice over the corresponding controls.

node excision prior to T. cruzi inoculum increases mice susceptibility to infection, as ascertained by the numbers of circulating parasites $[9,10]$.

The increase in cellularity of spleen and subcutaneous lymph node is a consequence of tissue T-/B-lymphocyte activation and expansion $[9,11,38,39]$. Parasite-driven proteins seem to contribute to the polyclonal activation of lymphocytes in Chagas disease. In this regard, transsialidase seems to contribute to lymphocyte activation and cytokine production by interfering with interaction between dendritic cells and $\mathrm{T}$ lymphocytes $[40,41]$. Other parasite-derived molecules such as racemase and T. cruzi DNA were proven to induce B-cell proliferation [42-44]. Although there are data showing that the polyclonal B-cell activation contributes to the pathological alterations seen in Chagas disease, evidence indicates that the majority of B cells are not parasite specific during early T. cruzi infection [41, 45-52].

Limited studies of B-cell dynamics among secondary organs during T. cruzi infection have been reported. $\mathrm{CD} 19^{+} \operatorname{IgD}{ }^{\text {low }}$ and $\mathrm{CD}_{1} 9^{+} \mathrm{IgD}^{\text {high }}$ represent two functionally distinct B-cell subsets $[53,54]$. CD $19^{+} \operatorname{IgD}^{\text {low }}$ are located in the spleen and central lymphoid organs, at the marginal zones, acting as the first line responders to pathogens in the blood. These cells are able to migrate to germinal centers and participate in T-cell-dependent responses. $\mathrm{CD} 19^{+} \mathrm{IgD}{ }^{\text {high }}$ cells are found in the lymph and B-cell follicles of the spleen. We have shown that, 14 days after infection, both types of $\mathrm{B}$ cells are significantly expanded in the lymphoid organs such as spleen and subcutaneous lymph nodes (see Figures 1(e) and $1(\mathrm{f})$ ). Since these B-cell subsets have distinct roles in 
the development of B-cell responses, related to their different localization, the increase of these two populations with polarized functions suggest a polyclonal B-cell activation during acute experimental Chagas. In agreement with this observation, previous reports suggests that $\mathrm{CD}^{+} \mathrm{B}$ cells are related to self-antigen immune response $[55,56]$.

In contrast to the hyperplasia seen in spleen and subcutaneous lymph nodes of infected mice, there is an atrophy of the mucosal associated lymphoid organs, which is related to a local decrease in IL-2 production, with a reduction of the total number of T/B lymphocytes [9]. One possible mechanism involved in IL-2 suppression in mesenteric lymph nodes could be associated with the differential distribution of regulatory $\mathrm{T}$ cells (Treg cells) among distinct lymphoid organs in infection, since IL-2 could be produced in normal levels and be sequestered by $\mathrm{CD} 25^{\text {high }} \mathrm{CD} 4^{+} \mathrm{FOXP} 3^{+}$cells, which have been demonstrated to be present in secondary lymphoid organs during infection $[9,57]$. In this vein, the cytokine deprivation induced by Treg cells is one of the mechanisms that might be associated with apoptosis in $\mathrm{T}$ cells [58].

Considering that gut-associated lymphoid tissues drain antigens from the small intestine and that chronic infection may progress with damage to the digestive tract, mesenteric lymph nodes and Payer's patches might be related to gut pathologies seen in infected patients. Lymphocytes and dendritic cells that are primed in Payer's patches migrate to mesenteric lymph nodes through draining lymphatic vessels $[9,59]$. Moreover, patients with digestive forms of the disease present high parasitemia and decreased T-/B-lymphocyte numbers in their blood $[60,61]$.

\section{Concluding Remarks and Perspectives}

Our studies have revealed that the lymphocyte population size displayed significant fluctuations in the lymphoid tissues along the infection (Figure 2). Acute infection in mice leads to strong activation of innate and adaptive immune response. Splenomegaly and expansion in subcutaneous lymph nodes were reported, with persistent $\mathrm{T}$ - and B-cell polyclonal activation. Conversely, atrophy in mesenteric lymph nodes (MLN) and thymus was also observed in the infection.

Our data indicate that the key intrathymic checkpoints necessary to promote negative selection process of thymocytes are effective during acute chagasic thymic atrophy. Although the negative selection process is still functional in the acute phase, DP cells are prematurely released to the periphery. During the course of experimental infection, these peripheral DP cells acquire an activated phenotype that is correlated with the cardiac clinical form of human chronic Chagas disease. Therefore, although the function of this DP T-cell population remains to be defined in vivo, the presence of peripheral activated DP cells with potentially autoreactive TCR may contribute to the immunopathologic events found in both murine and human Chagas disease.

Overall we believe that the dynamics of T-cell expansion and contraction in persistent pathogen infections, herein exemplified by Chagas disease, is not limited to the fluctuations of the lymphocyte population size, but also the redistribution of lymphocyte subsets in the lymphoid tissues along the infection. Fluctuations in the lymphocyte cell population may reflect specific and coordinated responses to the parasite in the lymphoid organs.

The classical paradigm for T-cell dynamics suggests that the resolution of a primary infection is followed by the generation of a long-lived and stable pool of memory lymphocytes. Since the physical basis of the response is stochastic, very limited alteration in this repertoire is expected to occur due to alterations of the dynamics of the lymphoid tissues. Understanding the basis of stochasticity in lymphocyte fluctuations that occur secondary to T. cruzi infection will hopefully improve our knowledge on the regional influences upon the lymphocyte dynamics, and this will likely be useful for the development of protective immune responses necessary to control persistent infections.

\section{Abbreviations}

T. cruzi: Trypanosoma cruzi;

DP T cells: $\mathrm{CD} 4^{+} \mathrm{CD} 8^{+}$double-positive T cells

AIRE: Autoimmune regulator gene

TRAs: Tissue-restricted antigens

TCR: T-cell receptor

TEC: $\quad$ Thymic epithelial cells.

\section{Conflict of Interests}

The authors declare that there is no conflict of interests.

\section{Acknowledgments}

This work was funded by grants from Fiocruz, CNPq, Faperj, and Capes (Brazil).

\section{References}

[1] E. R. Parker and A. Sethi, "Chagas disease: coming to a place near you," Dermatologic Clinics, vol. 29, no. 1, pp. 53-62, 2011.

[2] R. L. Tarleton, R. Reithinger, J. A. Urbina, U. Kitron, and R. E. Gürtler, "The challenges of Chagas disease-Grim outlook or glimmer of hope?” PLoS Medicine, vol. 4, no. 12, article e332, pp. 1852-1857, 2007.

[3] J. R. Coura and J. C. P. Dias, "Epidemiology, control and surveillance of Chagas disease-100 years after its discovery," Memorias do Instituto Oswaldo Cruz, vol. 104, supplement 1, pp. 31-40, 2009.

[4] G. Punukollu, R. M. Gowda, I. A. Khan, V. S. Navarro, and B. C. Vasavada, "Clinical aspects of the Chagas' heart disease," International Journal of Cardiology, vol. 115, no. 3, pp. 279283, 2007.

[5] K. M. Bonney and D. M. Engman, "Chagas heart disease pathogenesis: one mechanism or many?" Current Molecular Medicine, vol. 8, no. 6, pp. 510-518, 2008.

[6] F. R. S. Gutierrez, P. M. M. Guedes, R. T. Gazzinelli, and J. S. Silva, "The role of parasite persistence in pathogenesis of Chagas heart disease," Parasite Immunology, vol. 31, no. 11, pp. 673-685, 2009.

[7] R. Sathler-Avelar, D. M. Vitelli-Avelar, A. Teixeira-Carvalho, and O. A. Martins-Filho, "Innate immunity and regulatory Tcells in human Chagas disease: what must be understood?" 
Memorias do Instituto Oswaldo Cruz, vol. 104, supplement 1, pp. 246-251, 2009.

[8] W. Savino, D. M. S. Villa-Verde, D. A. Mendes-da-Cruz et al., "Cytokines and cell adhesion receptors in the regulation of immunity to Trypanosoma cruzi," Cytokine and Growth Factor Reviews, vol. 18, no. 1-2, pp. 107-124, 2007.

[9] J. De Meis, A. Morrot, D. A. Farias-de-Oliveira, D. M. S. VillaVerde, and W. Savino, "Differential regional immune response in Chagas disease," PLoS Neglected Tropical Diseases, vol. 3, no. 7, article e417, 2009.

[10] J. de Meis, L. M. S. Ferreira, L. V. C. Guillermo, E. M. Silva, G. A. DosReis, and M. D. F. Lopes, "Apoptosis differentially regulates mesenteric and subcutaneous lymph node immune responses to Trypanosoma cruzi," European Journal of Immunology, vol. 38, no. 1, pp. 139-146, 2008.

[11] J. De Meis, D. A. Mendes-Da-Cruz, D. A. Farias-De-Oliveira et al., "Atrophy of mesenteric lymph nodes in experimental Chagas' disease: differential role of Fas/Fas-L and TNFRI/TNF pathways," Microbes and Infection, vol. 8, no. 1, pp. 221-231, 2006.

[12] D. A. Mendes-da-Cruz, J. De Meis, V. Cotta-de-Almeida, and W. Savino, "Experimental Trypanosoma cruzi infection alters the shaping of the central and peripheral T-cell repertoire," Microbes and Infection, vol. 5, no. 10, pp. 825-832, 2003.

[13] V. Cotta-de-Almeida, A. Bonomo, D. A. Mendes-da-Cruz et al., "Trypanosoma cruzi infection modulates intrathymic contents of extracellular matrix ligands and receptors and alters thymocyte migration," European Journal of Immunology, vol. 33, no. 9, pp. 2439-2448, 2003.

[14] M. C. Leite de Moraes, M. Hontebeyrie-Joskowicz, F. Leboulenger, W. Savino, M. Dardenne, and F. Lepault, "Studies on the thymus in Chagas' disease. II. Thymocyte subset fluctuations in Trypanosoma cruzi-infected mice: relationship to stress," Scandinavian Journal of Immunology, vol. 33, no. 3, pp. 267-275, 1991.

[15] W. Savino, M. Do Carmo Leite-de-Moraes, M. HontebeyrieJoskowicz, and M. Dardenne, "Studies on the thymus in Chagas' disease. I. Changes in the thymic microenvironment in mice acutely infected with Trypanosoma cruzi," European Journal of Immunology, vol. 19, no. 9, pp. 1727-1733, 1989.

[16] M. D. C. Leite de Moraes, P. Minoprio, M. Dy, M. Dardenne, W. Savino, and M. Hontebeyrie-Joskowicz, "Endogenous IL10 and IFN- $\gamma$ production controls thymic cell proliferation in mice acutely infected by Trypanosoma cruzi," Scandinavian Journal of Immunology, vol. 39, no. 1, pp. 51-58, 1994.

[17] W. Savino, "The thymus is a common target organ in infectious diseases," PLoS Pathogens, vol. 2, no. 6, aticle e62, pp. 0472-0483, 2006.

[18] E. Roggero, A. R. Pérez, O. A. Bottasso, H. O. Besedovsky, and A. Del Rey, "Neuroendocrine-immunology of experimental Chagas' disease," Annals of the New York Academy of Sciences, vol. 1153, pp. 264-271, 2009.

[19] E. Silva-Monteiro, L. R. Lorenzato, O. K. Nihei et al., "Altered expression of galectin-3 induces cortical thymocyte depletion and premature exit of immature thymocytes during Trypanosoma cruzi infection," American Journal of Pathology, vol. 170, no. 2, pp. 546-556, 2007.

[20] B. P. Olivieri, A. P. de Souza, V. Cotta-de-Almeida, S. L. de Castro, and T. Araújo-Jorge, "Trypanosoma cruzi: alteration in the lymphoid compartments following interruption of infection by early acute benznidazole therapy in mice," Experimental Parasitology, vol. 114, no. 3, pp. 228-234, 2006.

[21] J. Mucci, E. Mocetti, M. S. Leguizamón, and O. Campetella, "A sexual dimorphism in intrathymic sialylation survey is revealed by the trans-sialidase from Trypanosoma cruzi," Journal of Immunology, vol. 174, no. 8, pp. 4545-4550, 2005.

[22] A. Henriques-Pons, J. DeMeis, V. Cotta-De-Almeida, W. Savino, and T. C. Araújo-Jorge, "Fas and perforin are not required for thymus atrophy induced by Trypanosoma cruzi infection," Experimental Parasitology, vol. 107, no. 1-2, pp. 14, 2004.

[23] E. Roggero, I. Piazzon, I. Nepomnaschy et al., "Thymocyte depletion during acute Trypanosoma cruzi infection in C57BL/6 mice is partly reverted by lipopolysaccharide pretreatment," FEMS Immunology and Medical Microbiology, vol. 41, no. 2, pp. 123-131, 2004.

[24] M. Mantuano-Barradas, A. Henriques-Pons, T. C. AraújoJorge, F. Di Virgilio, R. Coutinho-Silva, and P. M. Persechini, "Extracellular ATP induces cell death in $\mathrm{CD} 4^{+} / \mathrm{CD}^{+}$doublepositive thymocytes in mice infected with Trypanosoma cruzi," Microbes and Infection, vol. 5, no. 15, pp. 1363-1371, 2003.

[25] M. S. Leguizamón, E. Mocetti, H. G. Rivello, P. Argibay, and O. Campetella, "Trans-sialidase from Trypanosoma cruzi induces apoptosis in cells from the immune system in vivo," Journal of Infectious Diseases, vol. 180, no. 4, pp. 1398-1402, 1999.

[26] A. Morrot, E. Terra-Granado, A. R. Pérez et al., "Chagasic thymic atrophy does not affect negative selection but results in the export of activated $\mathrm{CD} 4^{+} \mathrm{CD}^{+} \mathrm{T}$ cells in severe forms of human disease," PLoS Neglected Tropical Diseases, vol. 5, no. 8, article e1268, 2011.

[27] A. R. Pérez, E. Roggero, A. Nicora et al., "Thymus atrophy during Trypanosoma cruzi infection is caused by an immunoendocrine imbalance," Brain, Behavior, and Immunity, vol. 21, no. 7, pp. 890-900, 2007.

[28] E. Corrêa-De-Santana, M. Paez-Pereda, M. Theodoropoulou et al., "Hypothalamus-pituitary-adrenal axis during Trypanosoma cruzi acute infection in mice," Journal of Neuroimmunology, vol. 173, no. 1-2, pp. 12-22, 2006.

[29] J. Mucci, A. Hidalgo, E. Mocetti, P. F. Argibay, M. S. Leguizamón, and O. Campetella, "Thymocyte depletion in Trypanosoma cruzi infection is mediated by trans-sialidaseinduced apoptosis on nurse cells complex," Proceedings of the National Academy of Sciences of the United States of America, vol. 99, no. 6, pp. 3896-3901, 2002.

[30] W. Savino, D. A. Mendes-Da-Cruz, S. Smaniotto, E. SilvaMonteiro, and D. M. Serra Villa-Verde, "Molecular mechanisms governing thymocyte migration: combined role of chemokines and extracellular matrix," Journal of Leukocyte Biology, vol. 75, no. 6, pp. 951-961, 2004.

[31] S. Zuklys, G. Balciunaite, A. Agarwal, E. Fasler-Kan, E. Palmer, and G. A. Hollander, "Normal thymic architecture and negative selection are associated with Aire expression, the gene defective in the autoimmune-polyendocrinopathycandidiasis-ectodermal dystrophy (APECED)," Journal of Immunology, vol. 165, no. 4, pp. 1976-1983, 2000.

[32] G. A. Hollander, B. Wang, A. Nichogiannopoulou et al., "Developmental control point in induction of thymic cortex regulated by a subpopulation of prothymocytes," Nature, vol. 373, no. 6512, pp. 350-353, 1995.

[33] M. Naspetti, M. Aurrand-Lions, J. DeKoning et al., "Thymocytes and RelB-dependent medullary epithelial cells provide growth-promoting and organization signals, respectively, to thymic medullary stromal cells," European Journal of Immunology, vol. 27, no. 6, pp. 1392-1397, 1997.

[34] M. Zhu, R. K. Chin, P. A. Christiansen et al., "NF- $\kappa$ B2 is required for the establishment of central tolerance through an Aire-dependent pathway," Journal of Clinical Investigation, vol. 116, no. 11, pp. 2964-2971, 2006. 
[35] D. A. Mendes-da-Cruz, J. S. Silva, V. Cotta-de-Almeida, and W. Savino, "Altered thymocyte migration during experimental acute Trypanosoma cruzi infection: combined role of fibronectin and the chemokines CXCL12 and CCL4," European Journal of Immunology, vol. 36, no. 6, pp. 1486-1493, 2006.

[36] A. Cossarizza, C. Ortolani, D. Monti, and C. Franceschi, "Cytometric analysis of immunosenescence," Cytometry, vol. 27, no. 4, pp. 297-313, 1997.

[37] L. Weiss, A. Roux, S. Garcia et al., "Persistent expansion, in a human immunodeficiency virus-infected person, of $\mathrm{V} \beta$-restricted $\mathrm{CD}^{+} \mathrm{CD}^{+} \mathrm{T}$ lymphocytes that express cytotoxicity- associated molecules and are committed to produce interferon- $\gamma$ and tumor necrosis factor- $\alpha$, Journal of Infectious Diseases, vol. 178, no. 4, pp. 1158-1162, 1998.

[38] P. M. Minoprio, A. Coutinho, and M. Joskowicz, "Polyclonal lymphocyte responses to murine Trypanosoma cruzi infection. II. Cytotoxic T lymphocytes," Scandinavian Journal of Immunology, vol. 24, no. 6, pp. 669-679, 1986.

[39] P. M. Minoprio, H. Eisen, and L. Forni, "Polyclonal lymphocyte responses to murine Trypanosoma cruzi infection. I. Quantitation of both T- and B-cell responses," Scandinavian Journal of Immunology, vol. 24, no. 6, pp. 661-668, 1986.

[40] A. R. Todeschini, M. P. Nunes, R. S. Pires et al., "Costimulation of host $\mathrm{T}$ lymphocytes by a trypanosomal trans-sialidase: involvement of CD43 signaling," Journal of Immunology, vol. 168, no. 10, pp. 5192-5198, 2002.

[41] W. Gao, H. H. Wortis, and M. A. Pereira, "The Trypanosoma cruzi trans-sialidase is a $\mathrm{T}$ cell-independent $\mathrm{B}$ cell mitogen and an inducer of non-specific Ig secretion," International Immunology, vol. 14, no. 3, pp. 299-308, 2002.

[42] B. Reina-San-Martín, W. Degrave, C. Rougeot et al., "A Bcell mitogen from a pathogenic trypanosome is a eukaryotic proline racemase," Nature Medicine, vol. 6, no. 8, pp. 890-897, 2000.

[43] M. A. Bryan and K. A. Norris, "Genetic immunization converts the Trypanosoma cruzi B-cell mitogen proline racemase to an effective immunogen," Infection and Immunity, vol. 78, no. 2, pp. 810-822, 2010.

[44] A. Buschiazzo, M. Goytia, F. Schaeffer et al., "Crystal structure, catalytic mechanism, and mitogenic properties of Trypanosoma cruzi proline racemase," Proceedings of the National Academy of Sciences of the United States of America, vol. 103, no. 6, pp. 1705-1710, 2006.

[45] P. Minoprio, O. Burlen, P. Pereira et al., "Most B cells in acute Trypanosoma cruzi infection lack parasite specificity," Scandinavian Journal of Immunology, vol. 28, no. 5, pp. 553$561,1988$.

[46] E. V. Acosta Rodriguez, E. I. Zuniga, C. L. Montes et al., "Trypanosoma cruzi infection beats the B-cell compartment favouring parasite establishment: can we strike first?" Scandinavian Journal of Immunology, vol. 66, no. 2-3, pp. 137-142, 2007.

[47] L. B. De Arruda Hinds, M. S. Alexandre-Moreira, D. DecotéRicardo, M. P. Nunes, and L. M. T. Peçanha, "Increased immunoglobulin secretion by B lymphocytes from Trypanosoma cruzi infected mice after B lymphocytes-natural killer cell interaction," Parasite Immunology, vol. 23, no. 11, pp. 581-586, 2001.

[48] N. Gironès, C. I. Rodríguez, E. Carrasco-Marín, R. F. Hernáez, J. López de Rego, and M. Fresno, "Dominant T- and B-cell epitopes in an autoantigen linked to Chagas' disease," Journal of Clinical Investigation, vol. 107, no. 8, pp. 985-993, 2001.
[49] C. Freire-De-Lima, L. M. T. Peçanha, and G. A. Dos Reis, "Chronic experimental Chagas' disease: functional syngeneic T-B-cell cooperation in vitro in the absence of an exogenous stimulus," Infection and Immunity, vol. 64, no. 7, pp. 28612866, 1996.

[50] N. Yoshida, J. E. Araya, J. Franco Da Silveira, and S. Giorgio, "Trypanosoma cruzi: antibody production and T cell response induced by stage-specific surface glycoproteins purified from metacyclic trypomastigotes," Experimental Parasitology, vol. 77, no. 4, pp. 405-413, 1993.

[51] P. Minoprio, A. Coutinho, S. Spinella, and M. HontebeyrieJoskowicz, "Xid immunodeficiency imparts increased parasite clearance and resistance to pathology in experimental Chagas' disease," International Immunology, vol. 3, no. 5, pp. 427-433, 1991.

[52] A. M. Rodriguez, F. Santoro, and D. Afchain, "Trypanosoma cruzi infection in B-cell-deficient rats," Infection and Immunity, vol. 31, no. 2, pp. 524-529, 1981.

[53] J. W. Tung and L. A. Herzenberg, "Unraveling B-1 progenitors," Current Opinion in Immunology, vol. 19, no. 2, pp. 150155, 2007.

[54] N. Baumgarth, M. Egerton, and A. Kelso, "Activated T cells from draining lymph nodes and an effector site differ in their responses to TCR stimulation," Journal of Immunology, vol. 159, no. 3, pp. 1182-1191, 1997.

[55] W. O. Dutra, D. G. Colley, J. C. Pinto-Dias et al., "Self and nonself stimulatory molecules induce preferential expansion of $\mathrm{CD}^{+} \mathrm{B}$ cells or activated $\mathrm{T}$ cells of chagasic patients, respectively," Scandinavian Journal of Immunology, vol. 51, no. 1, pp. 91-97, 2000.

[56] M. C. El Cheikh, M. Hontebeyrie-Joskowicz, A. Coutinho, and P. Minoprio, "CD5 B cells: potential role in the (auto)immune responses to Trypanosoma cruzi infection," Annals of the New York Academy of Sciences, vol. 651, pp. 557-563, 1992.

[57] F. S. Mariano, F. R. S. Gutierrez, W. R. Pavanelli et al., "The involvement of $\mathrm{CD}^{+}{ }^{+} \mathrm{CD} 25^{+} \mathrm{T}$ cells in the acute phase of Trypanosoma cruzi infection," Microbes and Infection, vol. 10, no. 7, pp. 825-833, 2008.

[58] P. Pandiyan, L. Zheng, S. Ishihara, J. Reed, and M. J. Lenardo, "CD $4{ }^{+} \mathrm{CD} 25^{+}$Foxp $^{+}$regulatory $\mathrm{T}$ cells induce cytokine deprivation-mediated apoptosis of effector CD4 ${ }^{+} \mathrm{T}$ cells," Nature Immunology, vol. 8, no. 12, pp. 1353-1362, 2007.

[59] H. H. Uhlig, C. Mottet, and F. Powrie, "Homing of intestinal immune cells," Novartis Foundation Symposium, vol. 263, pp. 179-188, 2004.

[60] E. M. Lemos, D. D. Reis, S. J. Adad, G. C. Silva, E. Crema, and R. Correa-Oliveira, "Decreased $\mathrm{CD} 4{ }^{+}$circulating T lymphocytes in patients with gastrointestinal Chagas disease," Clinical Immunology and Immunopathology, vol. 88, no. 2, pp. 150155, 1998.

[61] E. Crema, I. D. O. Monteiro, M. G. Z. Gomes, A. A. Silva, and V. Rodrigues Júnior, "Evaluation of cytokines (MIG, IFN- $\gamma$, TNF- $\alpha$, IL-4, IL-5, and IL-10) during the different evolutive phases of chagasic esophagopathy," Clinical Immunology, vol. 119, no. 2, pp. 213-218, 2006. 


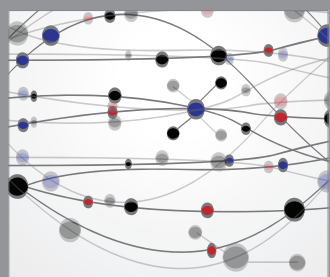

The Scientific World Journal
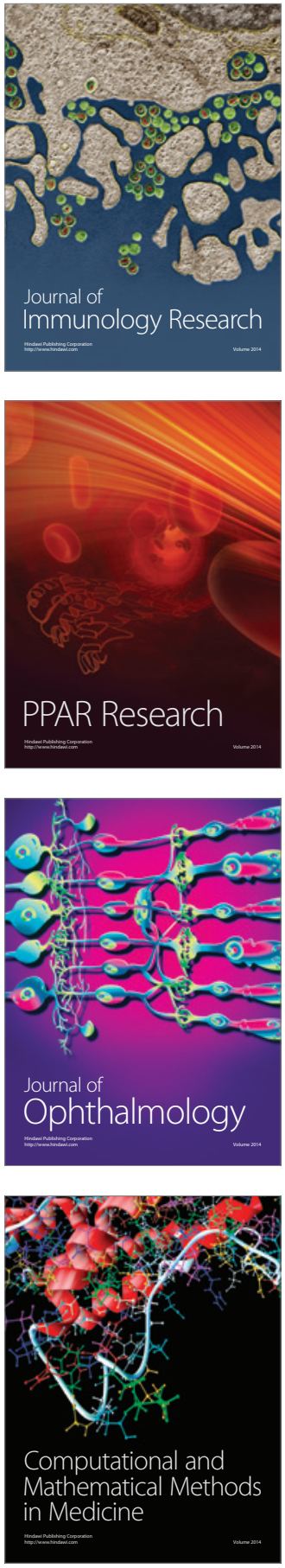

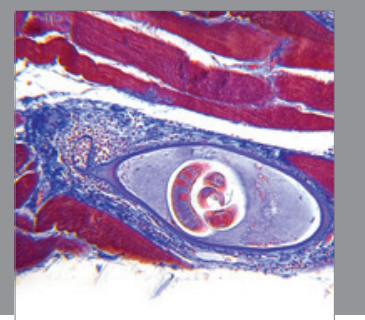

Gastroenterology

Research and Practice
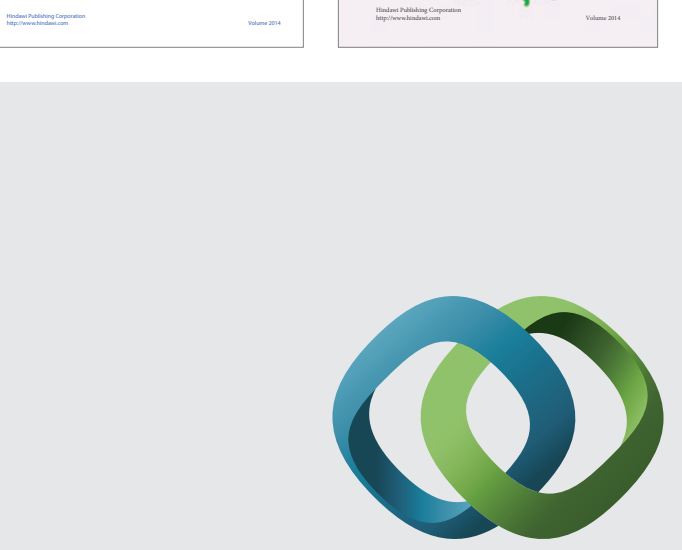

\section{Hindawi}

Submit your manuscripts at

http://www.hindawi.com
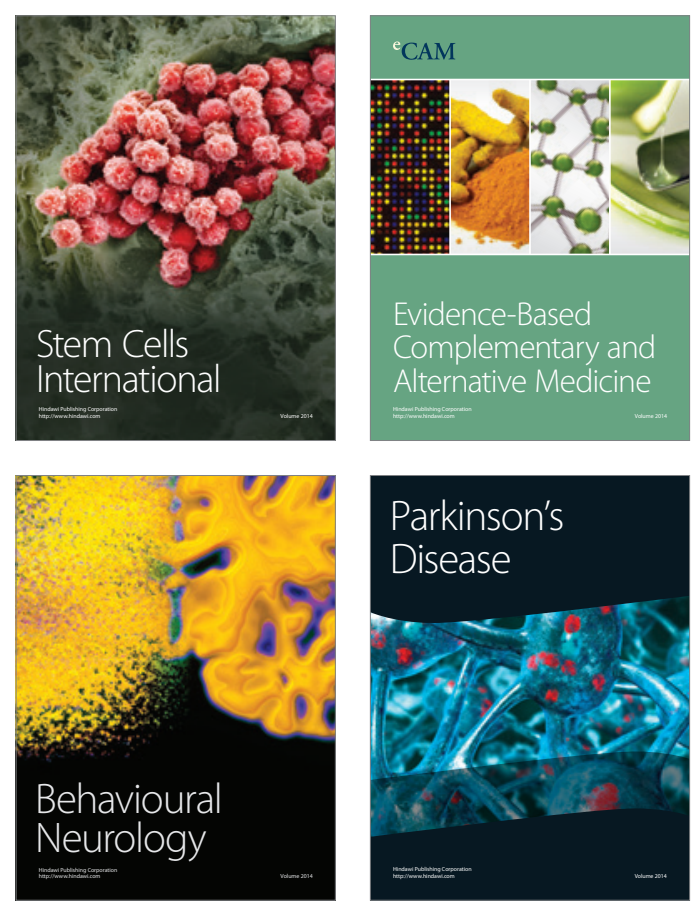

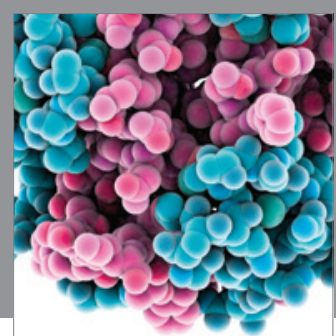

Journal of
Diabetes Research

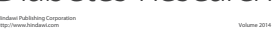

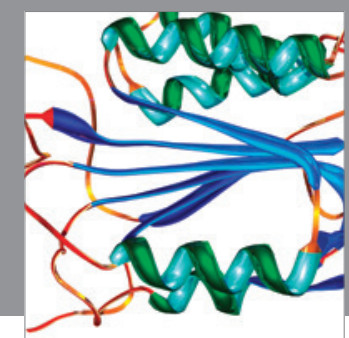

Disease Markers
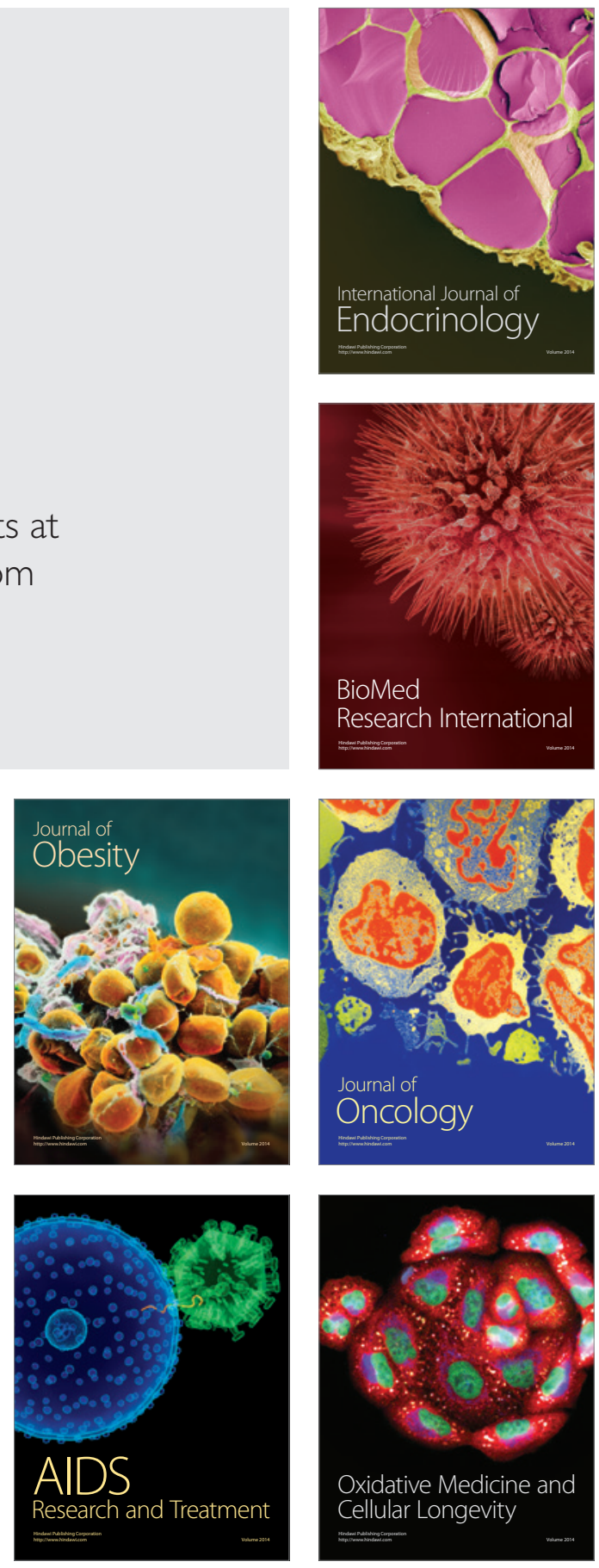